
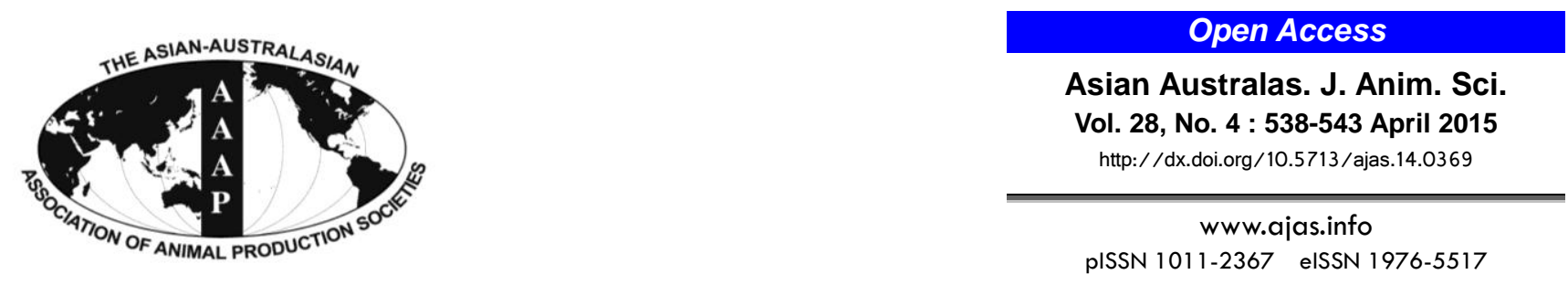

\title{
Effect of Olive Leaf (Olea europaea) Powder on Laying Hens Performance, Egg Quality and Egg Yolk Cholesterol Levels
}

\author{
H. Cayan* and G. Erener \\ Department of Animal Science, Faculty of Agriculture, University of Ahi Evran, Kirsehir 40100, Turkey
}

\begin{abstract}
This experiment was conducted to measure the effects of olive leaf powder on performance, egg yield, egg quality and yolk cholesterol level of laying hens. A total of 120 Lohmann Brown laying hens of 22 weeks old were used in this experiment. The birds were fed on standard layer diets containing $0,1 \%, 2 \%$, or $3 \%$ olive leaf powder for 8 weeks. Egg weight and yield were recorded daily; feed intake weekly; egg quality and cholesterol content at the end of the trial. Olive leaf powder had no effect on feed intake, egg weight, egg yield and feed conversion ratio $(p>0.05)$ while olive leaf powder increased final body weight of hens $(p<0.05)$. Dietary olive leaf powder increased yellowness in yolk color $(\mathrm{p}<0.01)$ without affecting other quality parameters. Yolk cholesterol content was tended to decrease about $10 \%$ ( $p>0.05$ ). To conclude, olive leaf powder can be used for reducing egg yolk cholesterol content and egg yolk coloring agent in layer diets. (Key Words: Egg Quality, Laying Hens, Oleuropein, Olive Leaf Powder, Yolk Cholesterol)
\end{abstract}

\section{INTRODUCTION}

Over the past few decades, there has been a considerable increase in the number of studies conducted with natural plants in order to enhance animal performance, egg yield and egg quality of laying hens (Lokaewmanee et al., 2009; An et al., 2010; Ghasemi et al., 2010; Mahmoud et al., 2010; Hu et al., 2011; Boka et al., 2014; Duru, 2013; Zhao et al., 2013). One such plant that has been the subject of considerable interest in recent years is the olive tree (Botsoglou et al., 2012), a mediterranean oil plant.

Olive trees are rich in phenolic substances with having significant biological properties, the most important of which is oleuropein. Whilst it was discovered in 1908 by Bourquelot and Vintilesco, the exact structure of this compound could only be determined in 1960 by Pannizzi et al. (1960). Oleuropein is the heterosidic ester of elenolic acid and hydroxytyrosol (Bouaziz et al., 2008).

Although oleuropein is found in all tissues and parts of olive trees-and can be present in olive pulp, olive oil, and the wastes (alperujo) generated during olive oil

\footnotetext{
* Corresponding Author: Huseyin Cayan. Tel: +90-386-280-48-22, Fax: +90-386-280-48-32, E-mail: huseyin.cayan@ ahievran.edu.tr Submitted May 16, 2014; Revised Jul. 12, 2014; Accepted Sept. 10, 2014
}

production - the most important natural source of this compound is the olive leaf (Soler-Rivas et al., 2000; Gikas et al., 2007). In previous studies, oleuropein content was determined as $0.005 \%$ to $2.0 \%$ in olive oil; $0.87 \%$ in alperujo; and 1.0 to $14.0 \%$ in olive leaves (Priego-Capote et al., 2004; Beauchamp et al., 2005).

Studies on olive leaf demonstrated that it includes some medical compounds having antihypertensive, antiatherogenic, cardioprotective, hypocholesterolemic, hypoglycemic, antimicrobial, antiviral, antitumor, antiinflammatory and antioxidant properties (Visioli et al., 2002; Botsoglou et al., 2013).

Conducted studies on laying hens, diets were supplemented with leaves from different plant sources (Thu chung, mustard, green tea, lacquer, mulberry, strawberry, thyme, ginkgo, etc.) in order to investigate their effects on laying performance and egg cholesterol level (ChevaIsarakul et al., 2001; Uluganbayar et al., 2005; Yang et al., 2007; Lokaewmanee et al., 2009; Ghasemi et al., 2010; Ayasan, 2011; Boka et al., 2014; Duru, 2013). However, there has been no study regarding the effects of olive leaf powder on the performance of laying hens, egg yolk coloring and egg cholesterol level. Therefore, the present study was carried out in laying hens to test whether dietary 
supplemented olive leaf powder affected on laying hens performance, egg yield, egg cholesterol level and the internal and external quality.

\section{MATERIALS AND METHODS}

\section{Animals, diets and feeding treatments}

A total of 120 Lohmann Brown laying hens of 22 weeks old with similar initial body weight $(1,756 \pm 31 \mathrm{~g})$ were divided into 4 experimental groups (control group and 3 treatment groups) each including 30 birds and kept individually in cages sized $35 \mathrm{~cm} \times 40 \mathrm{~cm} \times 45 \mathrm{~cm}$.

Olive leaves were collected from olive orchards in Yenipazar, a town and a small district of Aydın Province in the Aegean Region of Turkey, $45 \mathrm{~km}$ (28 mi) from the city of Aydin on the road to Denizli. This district is located between $37^{\circ}$ North latitude and $28^{\circ}$ East longitude in the Aegean Region where climatic conditions are hot in summer, and warm all year round. The collected leaves were milled $1 \mathrm{~mm}$ diameter particle size to get powder after drying with sunshine on a clean surface. $100 \mathrm{~g}$ olive leaf powder included $5.7 \mathrm{mg}$ oleuropein, $2 \mathrm{mg}$ beta carotene and $8 \mathrm{mg}$ lutein according to the laboratory analysis held in the Research Laboratory of TUBITAK (The Scientific and Technological Research Council of Turkey). For oleuropein analysis, in a $10 \mathrm{~mL}$ glass conical tube with a glass stopper, $5.0 \mathrm{~mL}$ of homogenized whole egg was added and mixed for $15 \mathrm{~s}$ on the vortex. Consequently, $0.5 \mathrm{~mL}$ of hydrochloric acid $0.5 \mathrm{M}$ was added in the tube and the whole was mixed for another $10 \mathrm{~min}$ on the vortex. Afterwards, $100 \mathrm{mg}$ of anhydrous sodium sulfate was added in the tube and mixed on the vortex until dissolution. Each sample was extracted with $3.0 \mathrm{~mL}$ of ethyl acetate with vortexing for $10 \mathrm{~min}$. The sample tube was centrifuged for $5 \mathrm{~min}$ at 2,000 rpm. After separation and transfer of the upper organic layer into a $10-\mathrm{mL}$ conical glass tube, the extraction procedure was repeated with $3.0 \mathrm{~mL}$ of ethyl acetate. The combined organic layers were evaporated to dryness at $50^{\circ} \mathrm{C}$ in the dry bath under a gentle stream of nitrogen. The residue was reconstituted in $250 \mathrm{~mL}$ of mobile phase and an aliquot of about $70 \mathrm{~mL}$ was injected onto the HPLC system (Grizis et al., 2011).

Dry matter $(98 \%)$, crude protein $(10.35 \%)$, ash $(6.10 \%)$, crude fat $(7.84 \%)$, crude fiber $(10.02 \%)$ contents of olive leaf powder was determined (AOAC, 1990). Birds were fed on basal (commercial) diets (178 g crude protein and 2,700 Kcal ME per kg diet) supplement with 0 (control), 1\%, 2\%, and $3 \%$ olive leaf powder for 8 weeks, based on NRC (1994) recommendations for poultry, Table 1. For experimental period, illumination was 16 hours light: 8 hours dark with ambient temperature $\left(19^{\circ} \mathrm{C}\right.$ to $\left.24^{\circ} \mathrm{C}\right)$. Feed and water were provided ad libitum.
Table 1. Composition of the basal diets (\%)

\begin{tabular}{|c|c|}
\hline Items & \\
\hline \multicolumn{2}{|l|}{ Feed ingredients } \\
\hline Corn & 28.80 \\
\hline Wheat & 20.00 \\
\hline Corn extract & 15.00 \\
\hline Soybean meal ( $46 \% \mathrm{CP})$ & 12.30 \\
\hline Limestone & 8.05 \\
\hline Sunflower meal (36\% CP) & 8.00 \\
\hline Meat and bone meal ( $35 \% \mathrm{CP})$ & 2.75 \\
\hline Poultry meal (60\% CP) & 2.75 \\
\hline Vegetable oil & 1.06 \\
\hline Fish meal $(72 \% \mathrm{CP})$ & 0.51 \\
\hline Mineral and Vitamin premix ${ }^{1}$ & 0.25 \\
\hline $\mathrm{NaCl}$ & 0.15 \\
\hline DL-methionine & 0.11 \\
\hline Toxin binding $^{2}$ & 0.10 \\
\hline Enzyme $^{3}$ & 0.10 \\
\hline $\mathrm{NaHCO}_{2}{ }^{3}$ & 0.08 \\
\hline Lysine & 0.01 \\
\hline \multicolumn{2}{|l|}{ Calculated composition } \\
\hline $\operatorname{ME}(\mathrm{kcal} / \mathrm{kg})$ & 2,700 \\
\hline $\mathrm{CP}$ & 17.80 \\
\hline $\mathrm{Ca}(\%)$ & 3.55 \\
\hline Lysine (\%) & 0.86 \\
\hline Methionine+systine (\%) & 0.69 \\
\hline $\mathrm{P}$ (available, \%) & 0.40 \\
\hline
\end{tabular}

$\mathrm{CP}$, crude protein; ME, metabolizable energy.

${ }^{1}$ The composition of vitamins and minerals in the premix (per ton of diet): vitamin $\mathrm{A}, 6,000,000 \mathrm{IU}$; vitamin $\mathrm{D}_{3}, 1,200,000 \mathrm{IU}$; vitamin $\mathrm{E}, 15,000$ $\mathrm{mg}$; vitamin $\mathrm{K}_{3}, 2,000 \mathrm{mg}$; vitamin $\mathrm{B}_{1}, 1,500 \mathrm{mg}$; vitamin $\mathrm{B}_{2}, 3,500 \mathrm{mg}$; niacin, $12,500 \mathrm{mg}$; pantotenat, $5,000 \mathrm{mg}$; vitamin $\mathrm{B}_{6}, 2,500 \mathrm{mg}$; vitamin $\mathrm{B}_{12}, 7.5 \mathrm{mg}$; folic acid, $500 \mathrm{mg}$; D-biotin, $22.5 \mathrm{mg}$; choline chloride, 62,500 mg; vitamin C 25,000 mg; iron, 30,000 mg; manganese, 40,000 mg; Zinc, 30,000 mg; copper, 2,500 mg; cobalt, $100 \mathrm{mg}$; iodine, $500 \mathrm{mg}$; selenium $75 \mathrm{mg}$.

2 Bentonite,montmorrilonite (E558), diotomaceous (E551c), inactive yeast.

${ }^{3}$ Endo 1,4 beta xylanase 6 phytase, endo 1,3 beta glucanase.

\section{Recording performance and egg quality}

The body weight of the hens was determined at the beginning and end of the study. Feed intake was recorded weekly by using electronic balance with $0.1 \mathrm{~g}$ sensitivity. Feed conversion ratio was calculated by dividing the total feed intake by total egg mass in the same week.

Egg quality analysis was performed monthly by using 10 eggs collected from each group in the last three days of the month. The breaking strength of the eggshells $\left(\mathrm{kg} / \mathrm{cm}^{2}\right)$ was measured by using a breaking strength measuring device (Stadelman, 1995). The collected eggs were marked individually, weighed, then, cracked to determine yolk, egg white, and egg shell with using an electronic balance $(0.1 \mathrm{~g}$ sensitivity). The height and width of both egg yolk and white were determined by micrometer. Yolk color was determined by using a Roche color fan (1 to 15$)$. The below 
egg quality parameters were calculated as;

\author{
Albumen index \\ $=$ albumen height $(\mathrm{mm})$ \\ /[albumen length (mm)+albumen width $(\mathrm{mm})] \times 100$
}

Yolk index

$=$ yolk height $(\mathrm{mm}) /$ yolk diameter $(\mathrm{mm}) \times 100$

Yolk ratio = yolk weight $(\mathrm{g}) / \mathrm{egg}$ weight $(\mathrm{g}) \times 100$

Albumen ratio

$=$ albumen weight $(\mathrm{g}) /$ egg weight $(\mathrm{g}) \times 100$

Shell ratio $=$ shell weight $(\mathrm{g}) /$ egg weight $(\mathrm{g}) \times 100$

\section{Determination of egg yolk cholesterol level}

Yolk cholesterol level was performed by using 40 eggs (10 eggs from each group) collected in the last week of the study. After transferring $0.5 \mathrm{~g}$ of egg yolk into a $50 \mathrm{~mL}$ cup, $1.0 \mathrm{~g}$ of sea-sand was added to the yolk. Following this, 20 $\mathrm{mL}$ of freshly prepared methanolic potassium hydroxide solution $(1.0 \mathrm{M})$ and $10 \mathrm{~mL}$ of isopropanol were also added, and the egg yolk mixture was heated inside a magnetic stirrer for 30 minutes. The addition of isopropanol was performed after the mixture's temperature cooled to 20 to $25^{\circ} \mathrm{C}$. The mixture was then filtered through a filter paper, and the resulting an eluent solution to be used in determining egg yolk cholesterol level. Based on the recommendations of the commercial kit (Boehringer Manheim Gmbh Biochemica, Darmstadt, Germany), the cholesterol content of the eggs was analyzed by using a spectrophotometer (T 60U) (Dresselhaus and Acker, 1974).

\section{Statistical analyses}

All data were analysed using the one way analysis of variance procedure of SPSS statistical package SPSS program (Windows Version of SPSS, release 15.00).
Duncan's Multiple Range Test used to identify the significant differences between the treatment means at $\mathrm{p}<0.05$ level (Duncan, 1955).

\section{RESULTS}

The results of present study are given in Table 2 and 3 . Based on our findings, the dietary olive leaf powder increased body weights of laying hens compared to control ones $(p<0.05)$. The increase in body weight was dose dependent. The lowest increase in body weight was observed in the control group, while the groups that received olive leaf powder in their feed demonstrated a greater increase in body weight. An evaluation of the data regarding feed intake by the end of the study indicated that dietary olive leaf powder did not affect feed intake and the feed conversion ratio $(p>0.05)$. By the end of the study, no differences were found between control group and the olive leaf powder consuming group with respect to egg yield and egg weight $(p>0.05)$. There was no difference between eggs collected from treatment hens with respect to their cholesterol content $(p>0.05)$. However, evidently but not statistically, the highest cholesterol content was observed in the control group at a value of $9.24 \mathrm{mg} / \mathrm{g}$. Diet supplemented with $3 \%$ olive leaf powder decreased about $10 \%$ egg cholesterol level compared to that of control eggs (Table 2). Also, it appears to have a measurable impact on egg yolk cholesterol level.

In accordance with inner and external egg quality parameters, dietary olive leaf powder did not cause any significant difference between groups ( $p>0.05)$, except for egg yolk color. Olive leaf powder improved significantly color score on behalf of yellow colouring $(p<0.01)$. Increasing the level of olive leaf powder in the diet also resulted in a linear increase in egg yolk color. The highest value egg yolk color was obtained in the groups receiving olive leaf powder at a dose of $2 \%$ and $3 \%$ (Table 3 ).

Table 2. Effect of dietary olive leaf powder on body weight, feed intake, feed conversion ratio, egg yield, egg weight and egg yolk cholesterol of laying hens

\begin{tabular}{|c|c|c|c|c|c|c|}
\hline \multirow{2}{*}{ Dietary treatments } & \multirow{2}{*}{ Control } & \multicolumn{3}{|c|}{ Dietary olive leaf powder $(\%)$} & \multirow{2}{*}{ SEM } & \multirow{2}{*}{ p-value } \\
\hline & & 1 & 2 & 3 & & \\
\hline Initial body weight $(\mathrm{g})$ & 1,756 & 1,757 & 1,757 & 1,756 & 6.14 & 0.957 \\
\hline Final body weight (g) & $1,803^{\mathrm{a}}$ & $1,839^{\mathrm{b}}$ & $1,844^{\mathrm{b}}$ & $1,849^{\mathrm{b}}$ & 8.61 & 0.047 \\
\hline Body weight gain (g) & 73.83 & 77.42 & 98.00 & 107.38 & 46.93 & 0.071 \\
\hline Daily feed intake (g) & 112 & 116 & 115 & 115 & 1,46 & 0.129 \\
\hline Feed conversion ratio ( $\mathrm{g}$ feed: $\mathrm{g}$ egg) & 2.07 & 2.06 & 2.07 & 2.05 & 0.050 & 0.478 \\
\hline Egg yield $(\%)$ & 94.80 & 96.90 & 94.80 & 96.40 & 0.800 & 0.170 \\
\hline Egg weight (g) & 60.10 & 60.10 & 58.80 & 59.50 & 0.215 & 0.090 \\
\hline Cholesterol (mg/g) & 9.24 & 8.46 & 8.60 & 8.34 & 0.196 & 0.388 \\
\hline
\end{tabular}

SEM, standard error of means.

${ }^{a, b}$ Means in the same row with different superscript letters are significantly different $(\mathrm{p}<0.05)$. 
Table 3. Effects of dietary olive leaf powder on external and internal quality of egg of laying hens

\begin{tabular}{|c|c|c|c|c|c|c|}
\hline \multirow{2}{*}{ Dietary treatments } & \multirow{2}{*}{ Control } & \multicolumn{3}{|c|}{ Dietary olive leaf powder $(\%)$} & \multirow{2}{*}{ SEM } & \multirow{2}{*}{ p-value } \\
\hline & & 1 & 2 & 3 & & \\
\hline Breaking strength $\left(\mathrm{kg} / \mathrm{cm}^{2}\right)$ & 3.73 & 3.90 & 3.82 & 3.65 & 0.096 & 0.815 \\
\hline Shell weight (g) & 6.63 & 7.04 & 6.73 & 6.67 & 0.105 & 0.516 \\
\hline Shell thickness $(\mu \mathrm{m})$ & 393 & 400 & 388 & 390 & 3.64 & 0.680 \\
\hline Yolk diameter (mm) & 33.90 & 33.70 & 34.70 & 33.90 & 0.167 & 0.144 \\
\hline Albumen length (mm) & 76.20 & 78.90 & 76.20 & 82.40 & 0.987 & 0.081 \\
\hline Albumen width (mm) & 62.90 & 62.90 & 62.00 & 65.40 & 0.799 & 0.470 \\
\hline Yolk height (mm) & 16.70 & 17.20 & 17.20 & 17.30 & 0.089 & 0.132 \\
\hline Albumen height (mm) & 6.55 & 6.73 & 6.81 & 7.09 & 0.082 & 0.121 \\
\hline Yolk weight $\quad(\mathrm{g})$ & 14.60 & 15.00 & 14.80 & 15.20 & 0.152 & 0.483 \\
\hline Albumen weight (g) & 38.70 & 38.00 & 38.50 & 40.30 & 0.344 & 0.093 \\
\hline Yolk color & $11.9^{\mathrm{b}}$ & $12.20^{\mathrm{ab}}$ & $12.90^{\mathrm{a}}$ & $13.00^{\mathrm{a}}$ & 0.109 & 0.001 \\
\hline Yolk index & 50.20 & 51.10 & 50.70 & 51.80 & 0.286 & 0.235 \\
\hline Albumen index & 9.34 & 9.55 & 9.87 & 10.00 & 0.131 & 0.185 \\
\hline Yolk ratio (\%) & 24.30 & 25.00 & 24.70 & 24.50 & 0.263 & 0.800 \\
\hline Shell ratio (\%) & 11.00 & 11.70 & 11.20 & 10.70 & 0.181 & 0.252 \\
\hline Albumen ratio (\%) & 64.60 & 63.10 & 64.10 & 64.80 & 0.340 & 0.296 \\
\hline
\end{tabular}

SEM, standard error of means.

${ }^{\mathrm{a}, \mathrm{b}}$ Means in the same row with different superscript letters are significantly different $(\mathrm{p}<0.05)$.

\section{DISCUSSION}

In the current literature, the amount of information regarding the effect of adding olive leaf powder to poultry diet has been limited, and there have been insufficient study regarding the effects of dietary olive leaf powder in laying hens.

In a study conducted in laying Japanese quail, Christaki et al. (2011a) reported that olive leaves had no significant effect on feed intake or the feed conversion ratio. However, they also reported that groups receiving olive leafsupplemented feed had a relatively higher feed intake than the control group. In a study in which laying hen feed was supplemented with olive pulp, Zangeneh and Torki (2011) observed that although feed mixtures with olive pulp and enzymes did not have a significant effect on feed conversion ratio and feed intake ( $p>0.05)$, hens fed with 9\% olive pulp and enzymes had the highest egg weight in comparison to the other groups. Erener et al. (2009), on the other hand, reported that the supplementation of broiler diets with olive leaf extract led to a greater increase in body weight, and also to an improvement in the feed conversion ratio. The similar increase in body weight was observed in our current study. In the present study, even though there was increase in body weight with dietary olive leaf powder, egg production was not affected negatively. Hens received olive leaf powder increased their body energy sources without any decrease in egg weight and number. This will give the opportunity to animals to sustain their production level, i.e., longevity of egg production. Evidently, in our study, the last week of the experiment, the number of eggs obtained olive leaf powder consumed hens was higher than controls, but statistically not significant.

Wenk (2002) reported that the increase in performance associated with the supplementation of poultry diets with plant-origin materials are mainly due to their polyphenolic contents. Polyphenolic compounds help eliminate pathogenic microorganisms that might potentially spread in these animals' digestive organs, while also preventing the formation of toxins within the feed and increasing the activity of digestive enzymes. In the present study, there was no incidence regarding animal diseases, in both treatment and control animals since our experimental conditions were well controlled and healthy. However, the present improvement in body weight during this study might be attributed to the polyphenolic compounds of olive leaves.

According to Loetscher et al. (2013), color is an important quality trait of foods since it affects the consumers' perception of quality and intensity of aroma and flavor and their decision on purchase. Most consumers associate yolk color to age and health status of the animal and to the quality of eggs and egg products, but objectively this is not the case. As usually known, feed additives and methods (e.g. free range) are primary factors in pigmentation of egg yolk. For consumers, one of the most important characteristics of eggs is the color of the egg yolk. Both consumers and individuals/businesses that process egg products (e.g. pastry shops) have a greater preference for eggs with darker-colored yolks (Lokaewmanee et al., 2009). Changes observed in yolk color are largely associated with the ingredients used in diets. In other words, by changing 
the composition of the diet, it is possible to change yolk color in accordance with the demands and preferences of the consumers. Carotenoids play an important role in the development of different color scores and tones in egg yolk. Especially, lutein is active yolk colorant. It was observed that increasing the amount of olive leaf powder in the diet resulted in a linear increase in egg yolk color. The strongest egg yolk color was obtained in the groups receiving olive leaf powder at a dose of $2 \%$ and $3 \%$. This increase in egg yolk color can be attributed to the carotenoid contents of olive leaf powder. Adding olive leaf powder to layer diet most likely increased the coloring compounds in the experimental diet plus coloring ingredients from corn. In fact, yellow corn - which is widely used in poultry dietscontains $51 \mu \mathrm{g} / 100 \mathrm{~g}$ of beta carotene and of $780 \mu \mathrm{g} / 100 \mathrm{~g}$ of lutein (Y1lmaz, 2010), while the olive leaf powder used in this study contained 2,006 $\mu \mathrm{g}$ beta carotene/100 $\mathrm{g}$ of and $8,180 \mu \mathrm{g}$ lutein/100g. Similarly, both Christaki et al. (2011a,b) and Zangeneh and Torki (2011) observed that olive leaf powder increased the egg yolk color. Also, there have been some studies on the effects of nettle, mulberry leaf, ginkgo leaf on yolk coloring (Lokaewmanee et al., 2009; Zhao et al., 2013). For example, Loetscher et al. (2013) improved yolk coloring with dietary nettle.

The oleuropein is one of the basic phenolic compounds in olive leaf. In the current study, it was found that oleuropein content of olive leaf transferred to eggs as evidenced the biochemical analysis of the collected eggs in the last week of experimental period, showing a significant difference in the oleuropein contents between control eggs and treatment eggs $(\mathrm{p}<0.01)$ as seen that oleuropein content of eggs were $0.398 \mu \mathrm{g} / 100 \mathrm{~g}, 1.448 \mu \mathrm{g} / 100 \mathrm{~g}$, and 2.366 $\mu \mathrm{g} / 100 \mathrm{~g}$, respective to dietary olive leaf powder at $1 \%, 2 \%$, and $3 \%$ doses.

In the beginning of study, it was hypothesised that oleuropein would decrease the cholesterol level of egg, but it was not happened statistically based on the biochemical analysis of the collected eggs in the last week of the study ( $>0.05$ ) even though 3\% olive leaf powder decreased numerically cholesterol level about $10 \%$. This insignificant decrease might be a start of the further studies on cholesterol and energy metabolism of layers. Oleuropein did not affect cholesterol content of egg, but it might cause the changes the blood cholesterol in experimental hens. On the literature, in Japanese quails, Sarica and Topbas (2014) and Christaki et al. (2011b), in broiler chicks, Erener et al. (2009) observed that there were decreases in blood cholesterol level of birds. On the other hand, Zangeneh and Torki (2011) did not found any effect of olive leaf on blood cholesterol level in layers. The current slight decrease in cholesterol level is possibly due to the hypocholesterolemic effect of oleuropein, whose concentration in eggs increased evidently in dose dependent manner. As oleuropein, most of the phenolic compounds in the olive leaf have been shown to possess hypocholesterolemic activities due to lowering the concentrations of serum and hepatic triglyceride, and altering the metabolism of cholesterol (Sarica and Topbas, 2014). These compounds are known to provide a protective effect against the oxidation of low-density lipoproteins (LDL), which are involved in the development of atherosclerosis and cardiovascular diseases. The hydroxytyrosol and oleuropein found in olive leaves are known to prevent LDL oxidation and to inhibit 3-hydroxy3-methyglutaryl coenzyme A - an enzyme that plays an important role in cholesterol synthesis. These properties of hydroxytyrosol and oleuropein might have contributed to the decreases in yolk cholesterol levels (Patrick and Uzick, 2001).

\section{CONCLUSION}

In conclusion, present study indicated that the dietary supplementation of olive leaf powder at a ratio of $3 \%$ in layer diet led to an increase in egg yolk color, due to its carotenoid content, and also to a numerical, but not significant, reduction in egg yolk cholesterol, most likely, due to its polyphenolic compounds. However, the studies on the supplementation of olive leaf powder in poultry diet have been, still, limited. Our findings can be considered as the first report presenting the effect of the olive leaf powder on egg production, egg quality (internal and external) and yolk cholesterol content of laying hens. Also, olive leaf powder may be an alternative feed additive for poultry to be used in poultry feed sector although more detailed studies have been, still, needed to elucidate the effects of olive leaf powder on poultry nutrition in different environmental and nutritional conditions.

\section{ACKNOWLEDGMENTS}

This study is a part of the MSc Thesis of H. Cayan which was financially supported by the Scientific Research Fund of the Ondokuz Mayis University (Project No: PYO.ZRT.1904.11.006).

Some results of this study was presented in National Animal Nutrition Congress held in Ankara, on 26 to 27 September 2013.

\section{REFERENCES}

An, B. K., H. S. Kwon, B. K. Lee, J. Y. Kim, S. J. You, J. M. Kim, and C. W. Kang. 2010. Effects of dietary skullcap (Scutellaria baicalensis) extract on laying performance and lipid oxidation of chicken eggs. Asian Australas. J. Anim. Sci. 23:772-776.

AOAC. 1990. Association of Official Analytical Chemists. Official Method of Analysis. 15th.Ed. Washington, DC, USA.

Ayasan, T. 2011. Black cumin and usage of poultry nutrition 
(Abstract in English). 7th National Animal Science Congress. Adana, Turkey. p. 1228-1236.

Beauchamp, G. K., R. S. J. Keast, D. Morel, J. Lin, J. Pika, Q. Han, C. Lee, A. B. Smith, and P. A. S. Breslin. 2005. Ibuprofen-like activity in extra-virgin olive oil. Nature 437:45-46.

Boka, J., A. H. Mahdavi, A. H. Samie, and R. Jahanian. 2014. Effect of different levels of black cumin (Nigella sativa L.) on performance, intestinal Escherichia coli colonization and jejunal morphology in laying hens. J. Anim. Physiol. Anim. Nutr. 98:373-383.

Botsoglou, E. N., A. K. Govaris, I. A. Ambrosiadis, and D. J. Fletouris. 2013. Olive leaves (Olea europaea L.) versus $\alpha$ tocopheryl acetate as dietary supplements for enhancing the oxidative stability of eggs enriched with very-long-chain $n-3$ fatty acids. J. Sci. Food Agric. 93:2053-2060.

Botsoglou, E., A. Govaris, D. Fletouris, and S. Iliadis. 2012. Olive leaves (Oleaeuropea L.) and a-tocopheryl acetate as feed antioxidants for improving the oxidative stability of a-linolenic acid-enriched eggs. J. Anim. Physiol. Anim. Nutr. 97:740-753.

Bouaziz, M., H. Hammami, Z. Bouallagui, H. Jemai, and S. Sayadi. 2008. Production of antioxidants from olive processing by-products. EJEAFChe. 7:3231-3236.

Cheva-Isarakul, B., S. Tangtaweewipat, P. Sangsrijun. 2001. The effect of mustard meal in laying hen diets. Asian Australas. J. Anim. Sci. 14:1605-1609.

Christaki, E., E. Bonos, and P. Florou-Paneri. 2011a. Effect of dietary supplementation of olive leaves and/or tocopheryl acetate on performance and egg quality of laying Japanese quail (Coturnix japonica). Asian J. Anim. Vet. Adv. 6:12411248.

Christaki, E. V., E. M. Bonos, and P. C. Florou-Paneri. 2011b. Comparative evaluation of dietary oregano, anise and olive leaves in laying Japanese quails. Brazil. J. Poult. Sci. 13:97101.

Dresselhaus, M. and L. Acker. 1974. Investigation of Methodology to Determine Egg Content in Pastry Products. Getreide Mehl Brot. 28:137-142.

Duncan, D. B. 1955. Multiple range and multiple $\mathrm{F}$ tests. Biometrics 11:1-42.

Duru, M. 2013. Effects of dietary strawberry (Fragariaxananassa Duch.) leaf powder on egg yield, quality and egg yolk cholesterol in laying hens. J. Food Agric. Environ. 11:477-480.

Erener, G., N. Ocak, E. Ozturk, S. Cankaya, and R. Ozkanca. 2009. The effects of olive leaf extract on performance, some blood parameters and cecal microflora of broilers. The Scientific and Technological Research Council of Turkey, Agriculture, Forestry and Veterinary Research Group, AFVRG-Project No: 1070820 report of final results.

Ghasemi, R., M. Zarei and M. Torki. 2010. Adding medicinal herbs including garlic (Allium sativum) and thyme (Thymus vulgaris) to diet of laying hens and evaluating productive performance and egg quality characteristics. Am. J. Anim. Vet. Sci. 5:151-154.

Gikas, E., F. N. Bazoti, and A. Tsarbopoulos. 2007. Conformation of oleuropein, the major bioactive compound of Oleaeuropea. J. Mol. Struct.: Theochem. 821:125-132.

Grizis, C., J. A. Politou, M. A. Koupparis. 2011. Simultaneous Determination of Oleuropein and Tyrosol in Plasma Using High Performance Liquid Chromatography with UV Detection. J. Liq. Chromatogr. Relat. Technol. 26.599-616.
Hu, C. H., A. Y. Zuo, D. G. Wang, H. Y. Pan, W. B. Zheng, Z. C. Qian, and X. T. Zou. 2011. Effects of broccoli stems and leaves meal on production performance and egg quality of laying hens. Anim. Feed Sci. Technol. 170:117-121.

Loetscher, Y., M. Kreuzer, and R. E. Messikommer. 2013. Utility of nettle (Urtica dioica) in layer diets as a natural yellow colorant for egg yolk. Anim. Feed Sci. Technol. 186:158-168.

Lokaewmanee, K., S. Mompanuon, P. Khumpeerawat, and K. Yamauchi. 2009. Effects of dietary mulberry leaves (Morus alba L.) on egg yolk color. J. Poult. Sci. 46:112-115.

Mahmoud, K. Z., S. M. Gharaibeh, H. A. Zakaria, and A. M. Qatramiz. 2010. Garlic (Allium sativum) supplementation: Influence on egg production, quality, and yolk cholesterol level in layer hens. Asian Australas. J. Anim. Sci. 23:1503-1509.

NRC. 1994. Nutrient Requirements of Poultry. 9th Ed. National Academy Press. Washington DC, USA.

Pannizzi, L., M. L. Scarpati, and G. Oriente. 1960. The constitution of oleuropein, a bitter glucoside of the olive with hypotensive action. Gazz. Chim. Ital. 90:1449-1485.

Patrick, L. and M. Uzick. 2001. Cardiovascular disease: C-reactive protein and the inflammatory disease paradigm: HMG-CoA reductase inhibitors, alpha-tocopherol, red yeast rice, and olive oil polyphenols. A review of the literature. Altern. Med. Rev. 6:248-271.

Priego-Capote, F., R. J. Jimenez, and M. D. Leaque de Castro. 2004. Fast separation and determination of phenolic compounds by capillary electrophores-diode array detection: Application to the characterization of alperujo after ultrasound assisted extraction. J. Chromatogr. A. 1045:239-246.

Sarica, S. and S. Toptas. 2014. Effects of dietary oleuropein supplementation on growth performance, serum lipid concentrations and lipid oxidation of Japanese quails. J. Anim. Physiol. Anim. Nutr. http://dx.doi.org/10.1111/jpn.12192.

Soler-Rivas, C., J. C. Espin, and H. J. Wichers. 2000. Oleuropein and related compounds. J. Sci. Food Agric. 80:1013-1023.

Stadelman, W. J. 1995. Quality idendification of shell egg. Egg Science and Tecnology (Eds. W. J Stadelman and D. J. Cotterill). Food Product Pres. pp. 39-66.

Uluganbayar, D., I. H. Bae, K. S. Choi, I. S. Shin, J. D. Firman, and C. J. Yang. 2005. Effects of green tea powder on laying performance and egg quality in laying hens. Asian Australas. J. Anim. Sci. 18:1769-1774.

Visioli, F., A. Poli, and C. Galli. 2002. Antioxidant and other biological activities of phenols from olives and olive oil. Med. Res. Rev. 22:65-75

Wenk, C. 2002. Herbs, botanicals and other related substances. WPSA-Bremen. Germany.

Yang, Y. X., J. D. Lohakare, and B. J. Chae. 2007. Effects of lacquer (Rhus verniciflua) meal supplementation on layer performance. Asian Australas. J. Anim. Sci. 20:82-88.

Y1lmaz, I. 2010. Carotenoids. J. Inonu Uni. Med. Fac. 17:223-231.

Zangeneh, S. and M. Torki. 2011. Effects of $b$-mannanase supplementing of olive pulp included diet on performance of laying hens, egg quality characteristics, humoral and cellular immune response and blood parameters. Global Vet. 7:391-398.

Zhao, L., X. Zhang, F. Cao, D. Sun, T. Wang, and G. Wang. 2013. Effect of dietary supplementation with fermented ginkgoleaves on performance, egg quality, lipid metabolism and eggyolk fatty acids composition in laying hens. Live. Sci. 155:7785 . 